\title{
Riscos alimentares: novos desafios para a sociologia ambiental e a teoria social
}

\section{Food risks: new challenges to environmental sociology and social theory}

\author{
Julia S. GUIVANT*
}

\section{RESUMO}

Neste artigo são analisadas as alternativas propostas por correntes construtivistas dentro da sociologia ambiental c por teorias sociais recentes (teoria da estruturação, da sociedade global de riscos e teoria do ator-rede) referentes ao problema de como lidar socialmente com riscos de graves conseqüencias, como os alimentares (BSE e transgênicos). Um dos pontos comuns na bibliografia aqui considerada é a crítica às análises técnicas e quantitativas sobre riscos ambientais e tecnológicos, dominantes internacionalmente na definição, avaliação e controle dos riscos. Estas análises ignorariam que tanto as causas dos danos como a magnitude de suas conseqüências estào mediadas por experiências e interações sociais, assim como por não reconhecerem a existência de diferentes racionalidades influenciando as percepçóes de riscos. Este argumento levanta a questão sobre como envolver os leigos em debates que têm sido monopolizados pelos peritos. Nas sugestões apresentadas e discutidas no artigo, podem ser identificados diversos problemas (idealização do conhecimento leigo como mais apropriado que o perito, generalizaçoes a partir do contexto europeu etc.). Finalmente, resgata-se a contribuição de recentes trabalhos na teoria do atorrede que, numa aproximação com a sociologia ambiental. formulam critérios mais viáveis para responder aos desafios colocados pelos riscos alimentares.

Palavras-chaves: riscos alimentares, sociologia ambiental, sociedade de risco. teoria da estruturação. teoria do ator-rede

* Programa de Pós-graduação em Sociologia Politica, Universidade Federal de Santa Catarina, Florianópolis, Brasil. juguivant@uol.com.br 


\section{ABSTRACT}

In this article. I analyze the alternatives proposed by the constructivist environmental sociology and by recent social theories (estrutucturation. global risk society and actor-network) to the problem of how to deal with risks of serious consequences, as the food risks (BSL: and GMOs). One of the issues that is common in this bibliography is the criticism in relation to the technical and quantitative analysis of environmental and technological risks. dominant at the international level in the acepted delinition, evaluation and control of risks. These analysis are seen as ignoring that both the causes and the magnitude of the conseguences are mediated by social experiences and interactions. and also not considering the existence of different rationalities influencing risk pereeption. This idea rise the cuestion of how to involve lay people in debates that have been monopolized by experts. In the suggestions presented and discuss in this article. some problems are identified (idealization of lay knowledge as more appropriate than the expert one, generalization from the European context, elc.). linally. the contribution of recent publications on the actor-network theory. closer to environmental sociology is positively evaluated in their formulation of more operational criteria to answer to the challenges rose by food risks.

Key-words: food risks. environmental sociology. risk society. estructuration theory. actor-network theory

\section{Introdução}

O tema dos riscos ambientais e tecnológicos tem passado a ocupar um lugar cada vez mais central na recente teoria social para caracterizar as sociedades da alta modernidade, envolvendo questões como as relações entre leigos e peritos, o papel da ciência e os desafios que estes riscos trazem para as políticas públicas. Mas a temática dos riscos não é nova dentro das ciências sociais. Uma vasta produção tem sido desenvolvida, em especial desde os anos 80, configurando uma dinâmica área subdisciplinar (GUIVANT', 1998).

Um dos pontos comuns nesta bibliografia sobre riscos é a crítica às análises técnicas e quantitativas, dominantes internacionalmente na definição, avaliação e controle dos riscos, por ignorarem que tanto as causas dos danos como a magnitude de suas consequiencias estão mediadas por experiências e interações sociais, assim como por não reconhecerem a existência de diferentes racionalidades influenciando as percepções de riscos. Os riscos alimentares têm sido destacados como um dos melhores exemplos para mostrar os limites dos métodos científicos de análise de riscos.

Entretanto, as críticas formuladas desde as ciências sociais aos métodos dominantes para avaliar os riscos, às vezes incorrem no problema oposto, isto é, numa certa idealização do conhecimento leigo sobre os riscos e numa imprecisão da categoria "leigos", como se esta se referisse a um grupo homogêneo de atores sociais.
Também os questionamentos parecem dirigir-se a uma versão destas análises bastante radical no referente à desconsideração dos conhecimentos leigos, deixando-se de lado formulações mais light. Se tomarmos estas em conta, ainda que mantendo diferenças substantivas, podemos observar alguma confluência - sem dúvida, em parte resultado das próprias críticas - no reconhecimento da importância de lidar com as incertezas do conhecimento científico nas análises de risco e da necessidade de considerar - ainda que em diferentes graus - o conhecimento leigo.

Outro ponto crucial em comum é o nível de imprecisão sobre como implementar estes alertas na avaliação e manejo dos riscos. O ritmo e a dimensão que tomaram os debates em torno dos riscos das sementes transgênicas apresentam um desafio sem precedentes particularmente para as análises sociais dos riscos. Sem dúvida a reação, fundamentalmente dos consumidores europeus, expõe os limites tão questionados das análises quantitativas e técnicas sobre os riscos. E neste sentido, pode destacar-se que a contribuição das análises sociais sobre os riscos permite dimensionar este debate no contexto da crise de confiança nos critérios, regras, instituições e produção científica envolvidos em garantir também a seguridade dos alimentos que consumimos. A reflexividade mais ampla sobre a saúde e a qualidade de vida tem emergido não só apesar da falta de acordo científico sobre os riscos, mas justamente por causa destes. As frequientes marchas e contramarchas da pesqui- 
sa científica sobre a relação entre alimentos e saúde acabam não só estimulando as incertezas entre o público consumidor como também provocando dúvidas em relação à confiabilidade das próprias informações científicas e das instituições que as emitem, acirrando os conflitos entre $O$ conhecimento leigo e o perito (BEARDSWORTH; KEIL, 1997). Por exemplo, qual é a dieta mais saudável, que alimentos estimulam o câncer, as doenças do coração etc.? O consumidor deve navegar num mar de informações difundidas nos meios de comunicação e transmitidas pelos médicos que podem ser altamente contraditórias e também desmentidas em tempo acelerado.

Como traduzir as contribuições das perspectivas que questionam os métodos dominantes para a análise dos riscos de graves conseqüências (invisíveis, irreversíveis e globais) em procedimentos operacionais, não só frente a um conflito entre leigos e peritos, mas que também envolve influências políticas, poder das corporações, velocidade da mudança tecnológica, efeitos econômicos diversos? Neste artigo argumenta-se que as abordagens construtivistas sobre os riscos (WYNNE, 1987; 1989; 1996; IRWIN, 1995; 2001; HANNINGAN, 1995; ADAM, 1995) e as teorias sociais como a da estruturação (GIDDENS, 1991; 1994; a,b), a da sociedade global de riscos (BECK, 1992), apresentam sérias limitações nas suas propostas sobre como lidar com os riscos de graves consequiências, fundamentalmente pela falta de respostas precisas sobre como e por quem devem ser tomadas as decisões em relação a tais riscos. Um avanço significativo na operacionalização de um espaço de debate público mais democrático encontra-se na recente confluência da teoria do ator-rede com as análises sociais dos riscos (LATOUR, 1998; 1999; CALLON et al. 2001), abrindo novos desdobramentos para discutir o próprio papel da teoria social na gestão dos riscos de graves consequiências.

\section{Leigos, peritos e incertezas nas análises con- vencionais de risco}

A seguridade alimentar inclui a produção primária dos alimentos (aspectos agrícolas e veterinários), processos industriais, estocagem, distribuição e comercialização, e envolve um amplo espectro de assuntos, como o controle dos elementos patogênicos, produtos químicos tóxicos, irradiação, aditivos e danos fisicos e temas como nutrição, qualidade dos alimentos, rotulação e educação (National Research Council, 1998, p. 17; European Union, White Paper on Food Safety, 2000).

Especialmente a partir dos anos 60 , os estudos técnicos e quantitativos sobre os riscos alimentícios passaram a ser realizados com a contribuição de várias disciplinas: toxicologia, epidemiologia, saúde pública, estatística, ciências dos alimentos, microbiologia, agronomia, medicina veterinária, tecnologia de alimentos, engenharias.

Os métodos formulados foram adotados como centrais para os procedimentos reguladores sistematizados por agências internacionais, como a FAO e a OMS, cujas recomendações orientam medidas a serem adotadas em diversos países, especialmente através do Codex Alimentarius - órgão subordinado a ambos organismos e destinado a formular padrões de segurança alimentar apropriados. Os critérios internacionais em relação à seguridade alimentar visam a garantir a proteção dos consumidores e facilitar o comércio internacional de alimentos. Este foi um dos importantes resultados da Rodada de Negociações de Uruguai, que se aplica a todos os países membros da OMC (Agreement on the Application of Sanitary and Phytosanitary Measures - APS Agreement).

Esta abordagem técnico-quantitativa considera 0 risco como um evento adverso, uma atividade, um atributo fisico, com determinadas probabilidades objetivas de provocar danos, e pode ser estimado através de cálculos quantitativos de níveis de aceitabilidade que permitem estabelecer standards, através de diversos métodos. Os standards de segurança alimentar se referem a níveis de riscos aceitáveis. Alguns exemplos incluem: 1) standards de risco-zero: usualmente implícitos nos níveis mínimos de tolerância; 2) standards de equilíbrio: segundo relações de custo-benefício, custo-eficiência; 3) standards de limites: nos quais um risco-zero é estipulado como aceitável e 4) standards de procedimento: em que o nível aceitável de risco é determinado por um acordo, através de negociação ou referendum.

Chega-se a estes standards através da análise de risco, que envolve três níveis: 1) avaliação dos riscos: abrange tanto a identificação científica dos standards dos riscos aceitáveis em relação a diferentes tipos de perigos alimentares, quanto o estabelecimento de procedimentos que assegurem que os riscos estejam mantidos dentro dos limites definidos por aqueles standards: 2) administração dos riscos: refere-se aos processos de 
ajuste de políticas públicas para implementar os standards, para minimizar ou reduzir os riscos e selecionar alternativas apropriadas; 3 ) comunicação dos riscos: orienta o processo interativo de intercâmbio de informações e opiniões sobre os riscos entre os que estimam, administram e as outras partes interessadas, os consumidores. Nesta comunicação dos riscos localizase un dos desafios mais importantes para os peritos. Os leigos tendem a ser identificados como receptores passivos de estímulos independentes, percebendo os riscos de forma não científica, pobremente informada e irracional.

Nos anos 70 e 80 emergiram entre acadêmicos, ambientalistas e setores indústrias diversas críticas em relação a estes métodos, tais como: falta de dados científicos quantitativos suficientes para relacionar a exposição a substâncias químicas e riscos à saúde; divergências graves de opinião dentro da comunidade científica sobre como interpretar as evidências e a incerteza dos resultados. Em parte, como resposta a estes questionamentos, os métodos quantitativos continuaram sendo desenvolvidos com recursos probabilísticos cada vez mais sofisticados, mas também procurando discriminar mais cuidadosamente as percepções dos leigos.

A partir dos últimos anos da década de 90 dois aspectos podem destacar-se em alguns documentos de órgãos internacionais ( $\mathrm{A} \Lambda \mathrm{O} / \mathrm{WHO}, 1995 ; 1997)$ e do National Research Council dos Estados Unidos (1996; 1998). Por um lado, afirma-se a necessidade de adoção de um sistema de segurança alimentar mais baseado na ciência, como o programa $11 \wedge \mathrm{CCP}$ (Hazard Analysis Critical Control Point), que possibilita a prevenção da disseminação de elementos patogênicos em todas as etapas do sistema alimentar. Por outro lado, reconhecese a existência de áreas de incerteza na avaliação de certo tipo de riscos alimentares, 1) trazidos pelos produtos químicos nos alimentos; 2) doenças como a vaca louca, que levam ao reconhecimento de que existem "ilhas de conhecimento num oceano de incerteza", e 3) alimentos transgênicos. Junto com a aceitação da incerteza, nestes documentos observa-se uma certa aproximação com idéias desenvolvidas pelas análises sociais sobre riscos: 1) a própria definição de segurança alimentar passa a ser entendida como um valor social; 2) reconhece-se a importância de fatores sociais influenciando o papel e o uso das gestões de risco e 3 ) recomenda-se que a percepção dos consumidores deve ser incorporada, não só no plano da comunicação, mas permeando os outros processos da análise dos riscos (National Research Council, 1998).

Estas são recomendações apresentadas cm relatórios encomendados a peritos, que mostram um distanciamento em relação às visões rígidas sobre o sistema de controle dos riscos alimentares, que se apoiavam na mera oposição entre conhecimentos leigos e científicos. Entretanto, não chegam a especificar claramente quais seriam as formas de operacionalizar isto ou quais seriam suas implicações práticas.

\section{Indeterminação, incerteza e conflitos entre lei- gos e peritos desde a Sociologia de Riscos}

O papel da incerteza na análise dos riscos ambientais e tecnológicos tem sido amplamente estudado desde a perspectiva construtivista na sociologia ambiental, desenvolvida a partir de meados dos anos 80 . Sem negar a existência de uma realidade objetiva nem o poder causal independente dos fenômenos naturais, levanta-se a necessidade de entender os conflitos que não só atravessam as relações entre peritos e leigos, mas também dividem a própria comunidade científica, pelo fato de que a definição de um incidente de poluição, um padrão de qualidade ambiental ou um alimento seguro dependem de julgamentos sociais em combinação com evidências científicas.

Um dos cientistas sociais que têm contribuído no questionamento das análises técnicas é B. Wynne (1987;1989;1996), que identifica fundamentalmente três problemas que comprometeriam significativamente o efetivo controle dos riscos:1) a falta de consideração do papel que tem entre os leigos a confiança no desempenho, as atitudes, a abertura ou transparência das instituições que controlam e regulam os riscos tecnológicos e ambientais; 2) a "sociologia ingênua" assumida pelos peritos, estudando os riscos como se o mundo real fosse equivalente ao mundo dos laboratórios, onde se controlam as operações, inspeção, manejo ou manutenção dos riscos, sem se reconhecer níveis diferentes de incerteza; 3 ) a falta de reconhecimento da indeterminação das práticas sociais pelos responsáveis da administração técnica dos riscos, que define de forma "standarizada" situações de risco, não problematizando as possibilida- 
sa científica sobre a relação entre alimentos e saúde acabam não só estimulando as incertezas entre o público consumidor como também provocando dúvidas em relação à confiabilidade das próprias informações científicas e das instituições que as emitem, acirrando os conflitos entre $O$ conhecimento leigo e o perito (BEARDSWORTH; KEIL, 1997). Por exemplo, qual é a dieta mais saudável, que alimentos estimulam o câncer, as doenças do coração etc.? O consumidor deve navegar num mar de informações difundidas nos meios de comunicação e transmitidas pelos médicos que podem ser altamente contraditórias e também desmentidas em tempo acelerado.

Como traduzir as contribuições das perspectivas que questionam os métodos dominantes para a análise dos riscos de graves conseqüências (invisíveis, irreversíveis e globais) em procedimentos operacionais, não só frente a um conflito entre leigos e peritos, mas que também envolve influências políticas, poder das corporações, velocidade da mudança tecnológica, efeitos econômicos diversos? Neste artigo argumenta-se que as abordagens construtivistas sobre os riscos (WYNNE, 1987; 1989; 1996; IRWIN, 1995; 2001 ; HANNINGAN, 1995; ADAM, 1995) e as teorias sociais como a da estruturação (GIDDENS, 1991; 1994; a,b), a da sociedade global de riscos (BECK, 1992), apresentam sérias limitações nas suas propostas sobre como lidar com os riscos de graves conseqüências, fundamentalmente pela falta de respostas precisas sobre como e por quem devem ser tomadas as decisões em relação a tais riscos. Um avanço significativo na operacionalização de um espaço de debate público mais democrático encontra-se na recente confluência da teoria do ator-rede com as análises sociais dos riscos (LATOUR, 1998; 1999; CALLON et al. 2001), abrindo novos desdobramentos para discutir o próprio papel da teoria social na gestão dos riscos de graves conseqüências.

\section{Leigos, peritos e incertezas nas ancilises con- vencionais de risco}

A seguridade alimentar inclui a produção primária dos alimentos (aspectos agrícolas e veterinários), processos industriais, estocagem, distribuição e comercialização, e envolve um amplo espectro de assuntos, como o controle dos elementos patogênicos, produtos químicos tóxicos, irradiação, aditivos e danos físicos e temas como nutrição, qualidade dos alimentos, rotulação e educação (National Research Council, 1998, p. 17; European Union, White Paper on Food Safety, 2000).

Especialmente a partir dos anos 60 , os estudos técnicos e quantitativos sobre os riscos alimentícios passaram a ser realizados com a contribuição de várias disciplinas: toxicologia, epidemiologia, saúde pública, estatística, ciências dos alimentos, microbiologia, agronomia, medicina veterinária, tecnologia de alimentos, engenharias.

Os métodos formulados foram adotados como centrais para os procedimentos reguladores sistematizados por agências internacionais, como a FAO e a OMS, cujas recomendações orientam medidas a serem adotadas em diversos países, especialmente através do Codex Alimentarius - órgão subordinado a ambos organismos e destinado a formular padrões de segurança alimentar apropriados. Os critérios internacionais em relação à seguridade alimentar visam a garantir a proteção dos consumidores e facilitar o comércio internacional de alimentos. Este foi um dos importantes resultados da Rodada de Negociações de Uruguai, que se aplica a todos os paises membros da OMC (Agreement on the Application of Sanitary and Phytosanitary Measures - APS Agreement).

Esta abordagem técnico-quantitativa considera 0 risco como um evento adverso, uma atividade, um atributo físico, com determinadas probabilidades objetivas de provocar danos, e pode ser estimado através de cálculos quantitativos de níveis de aceitabilidade que permitem estabelecer standards, através de diversos métodos. Os standards de segurança alimentar se referem a níveis de riscos aceitáveis. Alguns exemplos incluem: 1) standards de risco-zero: usualmente implícitos nos níveis mínimos de tolerância; 2) standards de equilíbrio: segundo relações de custo-benefício, custo-eficiência; 3) standards de limites: nos quais um risco-zero é estipulado como aceitável e 4) standards de procedimento: em que o nivel aceitável de risco é determinado por um acordo, através de negociação ou referendum.

Chega-se a estes standards através da análise de risco, que envolve três níveis: 1) avaliação dos riscos: abrange tanto a identificação científica dos standards dos riscos aceitáveis em relação a diferentes tipos de perigos alimentares, quanto o estabelecimento de procedimentos que assegurem que os riscos estejam mantidos dentro dos limites definidos por aqueles standards: 2) administração dos riscos: refere-se aos processos de 
des de reorganização do comportamento social para se adequar ou não aos modelos de comportamento social implícitos nos standards.

Sem poder aqui entrar em mais detalhes desta interpretação, nos exemplos que apresenta Wynne tendem a enfrentar-se, por um lado, leigos - geralmente com uma avaliação acurada dos riscos, mais abertos a mudanças circunstanciais e a novas informações, mas vítimas da desconsideração dos sistemas peritos - e, por outro, os peritos - com dificuldades de incorporar o conhecimento leigo e de ajustar o científico a novos contextos. Esta perspectiva polarizante e mais crítica do conhecimento perito que do leigo encontrar-se em outras análises sociais de risco (POWI:LL; LI:ISS, 1997; IRWIN, 1995). Faltaria uma explícita diferenciação interna de cada um destes setores, em particular no referente ao conhecimento leigo. De certa maneira, perde-se a contribuição de Douglas (1994) na diferenciação da pluralidade de racionalidades do público leigo.

Questionar uma tendência ao tratamento acrítico e essencialista do conhecimento leigo implica a necessidade de diferenciar tipos de conhecimento leigo assim como reconhecer que estes podem já ser resultado de uma hibridação de conhecimentos, com a absorção e transformação também de conhecimentos peritos. O conhecimento, assim, emerge como resultado de acomodações nas situações de interface entre diferentes mundos dos atores, sejam leigos ou peritos (L.ATOUR, 1987). Estas situações são definidas como pontos críticos de interseção entre diferentes sistemas, campos ou domínios sociais onde tendem a encontrar-se descontinuidades segundo diferenças de valores, interesses e mundosde-vida (ARCE; I.ONG, 1992; GUIVANT, 1997; GUIVANT; MIRANIDA, 1999).

Entretanto, se as análises técnico-quantitativas deixam, por enquanto, só no plano das propostas o apelo à integração da incerteza e das percepções dos consumidores nas diversas etapas de análises dos riscos alimentares, esta abordagem construtivista também carece de respostas claras sobre como operar em relação aos diferentes tipos de riscos analisados. Isto não diminui a sua contribuição ao aprofundar nos desdobramentos e desafios decorrentes de ter que lidar com inevitáveis potenciais fontes de risco de segunda ordem, como a ignorância e a indeterminação, assim como com incertezas que não necessariamente levam a futuras certezas e também com certezas contraditórias, que dividem de forma irreconciliável os sistemas peritos. Como propõe Wynne, estes aspectos deveriam situar-se no centro dos debates sobre as implicações sociais de uma determinada tecnologia ou substância perigosa, envolvendo os peritos num processo de aprendizagem social, para lidar com a condicionalidade do conhecimento e entender as bases socioinstitucionais de toda definição dos riscos. Desta maneira, se abririam espaços para negociações e debates sociais, sem procurar eliminar conflitos, ambigüidades ou indeterminações dos conhecimentos e das práticas sociais. Resta em aberto a questão de quais os leigos e peritos que participariam das negociações, já que, como foi acima colocado, ambas categorias envolvem uma heterogeneidade de atores sociais.

\section{A sociedade de risco e a política da vida}

Dois dos mais importantes e influentes teóricos sociais contemporâneos, Beck e Giddens consideram os riscos, em especial os ambientais e tecnológicos de graves conseqüências, como chaves para entender as características, os limites e transformações do projeto histórico da modernidade. À diferença da sociedade industrial, própria da modernidade, a sociedade da alta modernidade enfrenta estes riscos não como meros efeitos colaterais do progresso, mas como centrais a este e que ameaçam toda forma de vida no planeta. Sempre a humanidade conviveu com riscos, mas a especificidade dos atuais deriva da "incerteza manufaturada". Não se trata de que atualmente tenhamos uma vida com maiores riscos que antes, mas que estes são diferentes no que diz respeito as suas fontes e a sua abrangência. Os riscos aparecem com um caráter irredutível, sem garantias, sem certezas, com efeitos globais, invisíveis e, às vezes, irreversíveis, como seria o caso dos pesticidas e outros ingredientes químicos nos alimentos - freqüentemente tratados por estes autores como paradigmáticos da sociedade de risco.

O conceito central de "sociedade de risco", primeiro proposto por Beck e logo assumido por Giddens, aponta a que vivemos numa sociedade na qual leigos e peritos em áreas específicas devem fazer escolhas diariamente em termos de riscos, num contexto em que a estimação dos mesmos é em grande parte imponderável. Como na alta modernidade a ciência está desencantada e a certeza de seu conhecimento aparece minada, até nas 
ciências naturais, as decisões cotidianas acabam permeadas de dúvidas e ansiedade, frente às quais os atores sociais se protegem através de certos mecanismos de adaptação.

Definindo o risco como uma forma sistemática de tratar com os perigos e inseguranças induzidos e introduzidos pela própria modernização, Beck desenvolve uma brilhante crítica aos limites do modelo científico de análise de risco, particularmente tomando como exemplo o caso dos resíduos de pesticidas, que privilegia o conhecimento obtido em laboratório, em pesquisas com animais, resumido em fórmulas químicas e que considera os seres humanos só enquanto matéria orgânica.

Beck e Giddens coincidem na crítica aos limites das análises técnicas dos riscos, e aproximam-se - ainda que de forma não explícita - das abordagens culturais ao considerar que as fórmulas científicas sobre estimação de riscos levam implícitas definições sociais, culturais e políticas, envolvendo interesses de empresas, setores industriais, grupos científicos e profissionais. Segundo a definição técnica dos riscos que seja formulada, se delimitará quem é vencedor ou ganhador em termos econômicos: os riscos são também oportunidades de mercado. Desta maneira, questões como o que é desejável e aceitável em termos de risco estão impregnadas de valores. Beck se detém com mais cuidado na análise de como os peritos geralmente estão sob enorme pressão política e econômica.

No referente a como podem ser implementadas as suas propostas, Giddens (1994b, 1996) oscila entre sugestões muito vagas sobre os riscos de grandes consequiências, recorrendo à imagem de uma "utopia de cooperação global" e considerações detalhadas sobre como lidamos, individualmente, com riscos e incertezas. Neste caso, é muito otimista no papel da teoria social na formulação de prospectivas das sociedades futuras, mas tende a deixar sem resposta clara como a sociedade da alta modernidade pode lidar com os riscos artificialmente manufaturados.

Beck questiona os métodos técnicos na análise dos riscos pelos seguintes argumentos (MOl.; SPAARGARI:M, 1993): 1) limitado alcance dos métodos, devido a que não todas as substâncias podem ser avaliadas no seu potencial de risco, nem podem ser avaliados os efeitos das combinações nos nossos corpos e no meio ambiente; 2) não consideram os efeitos acumulativos a longo prazo; 3 ) projetam-se resultados estudados em animais para os seres humanos de uma forma controvertida, e 4) ignoram-se os fatores sociais que podem influenciar as peculiaridades da sensibilidade dos indivíduos.

As alternativas para o controle dos riscos de graves consequiências são menos difusas que as apresentadas por Giddens, com um caráter mais normativo. No livro Risk Society, Beck apresentava uma forte crítica ao papel da ciência na geração dos riscos ambientais de graves conseqüências, mas mantinha um apelo ao conhecimento científico como caminho de saída para tais riscos. Pelo fato de haver limites para que os standerds dos riscos potenciais possam ser determinados exclusivamente pelo conhecimento científico, não só devem ser tomadas decisões, mas também devem ser restabelecidas as regras e as bases em que se tomam tais decisões: abrindo-se o diálogo e o processo decisório e reconhecendo-se a ambigüidade e a ambivalência dos processos sociais como inevitáveis, sem se procurar soluções definitivas (BI:CK, 1994).

Neste sentido, a perspectiva construtivista seria chave para poder responder a questões como: "How, for example, is the borroed self-evidence of 'realistic' dangers actually produced? Which actors, institutions, strategies and resources are decisive in its fabrication?"(BE:CK, 1999, p. 24). Desde esta perspectiva, falar da sociedade global de riscos significa não se apoiar exclusivamente no diagnóstico científico para lidar com os riscos de graves conseqüências. Mas também Beck reconhece a posição realista de que os riscos da produção industrial "são" agora globais, demonstráveis por descobertas cicntificas, e exigem políticas formuladas por instituições transnacionais.

A sintese da posição de Beck é a de que os riscos existem, mas a sua transformação depende de como são percebidos socialmente. Beck vê um conteúdo interpretativo no que denomina "realismo reflexive", com um poderoso potencial a ser assumido nas estratégias de poder: "Such a reflexive realism does delve into the sources which make of "reality constructs'a 'reality'for the first time; it investigates how self-evidence is produced, how questions are curtailed, how alternative interpretations are shut up in black boxes, and so on" (BE:CK, 1999, p. 26). 
A este realismo reflexivo soma-se a proposta de um "construtivismo institucional", que seria a resposta de Beck à questão de como lidar com a natureza depois de que acabou como um âmbito separado da sociedade:

\begin{abstract}
"Nature" and the "destruction of nature" are institutionally produced and define (in "lay-expert conflicts") within industrially internalized nature. Their essential content correlates within institutional power to act and to mould. Production and definition are thus two aspects of the material and symbolic 'production' of 'nature and the destruction of nature': they refer, one might say, to discourse coalitions within and between quite different, ultimately world-wide, action networks"(BECK. 1999, p. 31 ).
\end{abstract}

Pelo fato de haver limites para que os standards dos riscos potenciais possam ser determinados exclusivamente pelo conhecimento científico, não só devem ser tomadas decisões, mas também devem ser restabelecidas as regras e as bases em que se tomam tais decisões: abrindo-se o diálogo e o processo decisório e reconhecendo-se a ambigüidade e a ambivalência dos processos sociais como inevitáveis, sem se procurar soluções definitivas.

Para isto, propõe-se fóruns de negociação, envolvendo autoridades e empresas, assim como sindicatos, representantes políticos etc. Estes fóruns não necessariamente procurariam o consenso, mas possibilitariam tomar medidas de precaução e prevenção, integrando as ambivalências, mostrando quem são os ganhadores e perdedores, fazendo isto assunto público, e finalmente, desta forma, melhorando as pré-condições para a ação política.

Alguns parâmetros básicos que devem nortear o próprio processo de negociação dentro de uma nova política para enfrentar os riscos seriam (BECK, 1995b; GUIVANT, 1998): 1) estabelecer correlações de standards como fundamento para o reconhecimento legal do dano, em lugar de uma estrita prova de causa, que muito dificilmente pode ser atingida, dada a interdependência global da produção de riscos; 2) mudar a responsabilidade da prova, de forma que os agentes industriais e os peritos devam passar a estar obrigados a se justificar em público; 3) responder às reclamações por segurança técnica com responsabilidade (liability) pelos danos; 4) reformular o princípio do poluidor-pagador, criando accountabilities regionais para setores econômicos beneficiados e prejudicados; 5) sugerir e negociar acordos sobre o reconhecimento do dano e sobre pagamentos compensadores entre as plantas industriais de uma região e sua população, e 6) instaurar comitês e grupos de peritos nas áreas cinzas da política, ciência e indústria, incorporando representantes de diferentes disciplinas, de grupos alternativos de peritos e de leigos.

Para estabelecer estes comitês ou fóruns de debate, Beck (1995a; 1998) descreve com bastante precisão os aspectos que implicariam: 1) a população deveria deixar para trás a noção de que os administradores e peritos sempre conhecem exatamente tudo, ou pelo menos melhor, sobre o que é recomendável para todos. Isto implica uma "desmonopolização" do trabalho dos peritos; 2) o círculo de atores que devem participar não pode permanecer fechado aos especialistas, mas aberto a outros atores sociais que estejam diretamente envolvidos no problema em questão; 3) todos os participantes do fórum devem aceitar que as decisões tenham um caráter aberto, uma vez tomadas para possibilitar ajustes posteriores; 4) deve-se garantir um espaço público para estes fóruns, de forma que as negociações não tenham lugar a portas fechadas, entre peritos e atores chaves nos processos decisórios, passando-se a ser aceito o caráter incontrolável dos processos de debate como elemento enriquecedor; 5) as normas dos fóruns - modos de discussão, protocolos, avaliações das entrevistas, formas de votar e aprovar as medidas - devem surgir de um acordo entre os participantes e passar a ser autolegisladas.

Beck, assim como Wynne, entra num terreno difuso nos quais leigos e peritos estariam envolvidos nestes procedimentos que sugere. Deixando implícito que, em certa forma, o grave problema sempre é a oposição entre leigos e peritos.

\section{A teoria do ator-rede e a democracia dialógica}

Uma das confluências mais interessantes entre a teoria da sociedade de risco e a sociologia do conhecimento científico tem acontecido recentemente com a teoria do ator-rede, formulada principalmente por Bruno Latour, Michel Callon e John Law, entre outros (ver LAW: HASSARD, 1999), sendo uma corrente de grande influência e capacidade de gerar polêmica no âmbito da sociolo- 
gia da ciência. A teoria do ator-rede passou por diversas fases, que foram se superpondo. Inicialmente os trabalhos eram sobre as redes sociotécnicas formadas nos laboratórios (LATOUR, 1987). A seguir podemos identificar novas pesquisas sobre processos de inovação tecnológica e científica já fora dos laboratórios (CALI.ON, 1986). Outro momento engloba uma série de trabalhos mais gerais sobre teoria social, questionando os conceitos de modernidade, de agência, e de prioridade dada aos humanos em contraposição a pressupor-se uma simetria entre eles e os não-humanos (híbridos, artefactos etc.) (LATOUR, 1994). Mais recentemente, este processo de expansão das análises deste grupo de pesquisadores passou a estabelecer relações estreitas entre a teoria do ator-rede e a sociologia ambiental, dada a existente preocupação com as relações entre ciências sociais e naturais, e entre os diversos tipos de atores sociais identificados.

Nesta última fase, alguns trabalhos dentro da teoria do ator-rede têm aberto um diálogo com a teoria da sociedade global de riscos (LATOUR, 1999; 1998; CALLON et al. 2001), coincidindo no chamado a que as ciências sociais passem a ter um papel central na organização do debate público sobre os riscos, assim como reconsideram o papel das relações entre pesquisa básica e aplicada. Ambas abordagens teóricas coincidem na centralidade para a teoria social de mostrar como não é mais possível separar o social do natural nem o sociológico do científico. Também compartilham a preocupação com os processos decisórios sobre riscos incertos, especialmente com o papel dos fóruns democráticos.

O debate público aberto pelos transgênicos é analisado em detalhe por CALLON et al. (2001), que defendem a abertura de fóruns como a melhor estratégia para o processo decisório em relação a riscos incertos e às controvérsias sociotécnicas, por se tratar de espaços abertos onde os grupos sociais podem mobilizar-se para debater a escolha de técnicas. Estes fóruns devem ser espaços híbridos, combinando peritos e leigos e também permitindo incluir tanto os temas dentro de um registro variado, como os éticos, econômicos e técnicos. Também, em oposição a uma democracia delegativa, que aumentaria o descontrole sobre os riscos incertos, os fóruns abririam um espaço de negociações de caráter democrático dialógico. Por isto, os fóruns propostos por Callon et al. diferenciam-se das pesquisas de opinião e os referendums, que não permitem diferenciar posições divergentes, ao encobrir estas dentro do conceito de "opinião pública".

Modelos de fóruns democráticos dialógicos seriam os grupos focais os ou de discussão, as pesquisas de consulta pública e os comitês locais de informação e consulta. Estes espaços públicos deveriam oferecer igualdade de condições de acesso aos debates, transparência e rastreabilidade dos debates, e claridade das regras que os organizam.

A proposta de CALL.ON et al. (2001, p. 215-230) avança significativamente na preocupação com operacionalizar estes critérios, analisando os significados de diferentes graus em que podem apresentar-se a partir de diversos exemplos tomados dos debates na França em torno dos transgênicos. Também os autores detalham os problemas que podem emergir nos fóruns, como a sua instrumentalização, como um simples meio de legitimizar decisões já tomadas.

Entretanto, apesar desta maior especificidade na análise e da rica agenda de pesquisa que abrem, os recentes trabalhos da teoria do ator-rede mantêm uma abordagem limitada às experiências da França. Assim como nas análises da sociologia ambiental e da teoria social acima comentadas, falta uma perspectiva mais abrangente e comparativa sobre a dinâmica global dos riscos de graves consequiências.

\section{Conclusões}

As análises sociais sobre os riscos ambientais e tecnológicos, seja desde uma perspectiva mais específica, seja desde uma mais teórica, têm contribuído significativamente para mostrar os limites das análises técnico-quantitativas destes riscos. Relatórios recentes elaborados por peritos internacionais na análise de riscos alimentares mostram certa incorporação dos questionamentos, ao reconhecer a necessidade de lidar com as incertezas do conhecimento cientifico e de incorporar as percepções e valores dos leigos não só na etapa final de comunicação dos riscos avaliados pelos cientistas.

A dimensão atingida pelos debates sobre os riscos dos transgênicos, deslocando as decisões do plano de afirmações científicas inquestionáveis para o terreno de uma demanda por uma ciência que deve explicitamente discutir valores e implicações políticas e econômicas, coloca desafios operacionais tanto para os peritos liga- 
dos a órgãos internacionais definidores de diretrizes para a segurança alimentar quanto para cientistas sociais já altamente críticos de uma ciência pretensamente neutra na análise dos riscos alimentares.

Colocando os transgênicos na perspectiva de uma sociedade global de riscos, pode-se observar que a interpretação do debate como uma simples oposição entre leigos e peritos não se sustenta. Se nos países europeus encontramos uma mobilização mais generalizada entre consumidores, não é o caso do Brasil, onde certos setores peritos junto com grupos organizados de defesa dos direitos dos consumidores e outras ONGs concentram as ações. Estes leigos e peritos, por sua vez, podem se estabelecer alianças - não necessariamente produto de acordos explícitos, mas de "afinidades eletivas" - com outros setores internacionais, gerando dinâmicas impremeditadas nas negociações em torno dos transgênicos.

Talvez uma das conseqüências da crise provocada pelos transgênicos seja a de ter gerado condições mais favoráveis para uma "desmonopolização do conhecimento perito" assim como para priorizar o princípio da precaução. A desagregação operacional desta proposta deveria considerar que tanto leigos quanto peritos são atores com racionalidades e interesses diversos, que podem estabelecer alianças cruzadas, "impuras", de formas mais ou menos explícitas, com especificidades regionais e nacionais e também articulando-se cada vez com mais facilidade no plano internacional, frente a determinados focos de risco; o que não garante a sua permanência frente a outros tópicos. A partir do reconhecimento desta "impureza", se poderia incorporar nas análises de riscos este outro nível de indeterminação social,

\section{REFERÊNCIAS}

ADAMS. J. Risk. Londres: University College London, 1995.

ARCE: $\Lambda$. : LONG. N. The dynamics ol knowledge. Interlaces between bureaucrats and peasants. In: LONG, N. : LONG. A. (Eds.). Battlefields of knowledge. The interlocking of theory and practice in social research and development. Londres: Roulledge. 1992.

BEARDSWORTH. A. ; KEIL. T. Sociology on the menu. An invitation to the study of food and society. Londres: Routledge, 1997. para estabelecer parâmetros, talvez mais realistas, de como deveriam ser os debates e as negociações sobre tais riscos. Mas isto já num contexto em que não seja mais esperada a falsa promessa do modelo de análise de risco técnico-quantitativo de que podemos esperar viver numa sociedade de risco-zero.

Desta maneira, um dos desafios frente a esta possível "desmonopolização do conhecimento perito", que se coloca fundamentalmente para as análises sociais dos riscos, será o de como lidar com as diferenças internas entre leigos e entre peritos, com diferentes alianças, dentro das peculiaridades regionais e nacionais, mas articuladas na complexa dinâmica da sociedade global de ris$\cos$. As perguntas sobre as quais não temos respostas nem tampouco estas poderiam ser expressas em fórmulas pré-determinadas - referem-se a quem decide (quais leigos, quais peritos, quem os representa) e como se decide (através de que procedimentos se estabelece a participação? Fóruns locais, nacionais, internacionais? Plebiscitos?) entre os riscos ambientais e tecnológicos aos que podemos estar expostos.

A contribuição da teoria do ator-rede tem sido de avançar nas respostas a estas questões, detalhando mais o caráter destes espaços públicos e os caminhos para construir uma democracia dialógica, como forma de fortalecer a democracia representativa. Mas ainda permanece em aberto para a sociologia ambiental e a teoria social a formulação integrada de uma perspectiva comparativa que considere as especificidades dos países do Norte e do Sul nas suas possibilidades de estabelecer estes fóruns e nas diferentes relações que se estabelecem entre leigos e peritos.
BECK, U. Risk society. Towards a new modernity. Londres: Sage Publications. 1992.

BECK. U. The reinvention of politics: towards a theory of rellexive modernization. In: BECK, U.: GIDDENS. A.: LASH, S. Reflexive Modernization. Politics, tradition and aesthetics in the modern social order. Cambridge: Polity Press, 1994.

BECK. U. Ecological politics in an age of risk. Cambridge: Polity Press, 1995a. 
BECK. U. Ecological enlightenment. Essays on the politics of the risk society. New Jersey: Humanity Press. 1995 b.

BECK, U. Politics of risk society. In: FRANKLIN, J. (lid.). The politics of the risk society. Cambridge: Polity Press. 1998.

BECK. U. World risk society. Londres: Polity Press. 1999.

CALLON. M. The sociology ol an actor-network: the case of the electric vehicle. In: CALLON. M.: LAW. J. : RIP. A. (I:ds.). Mapping the dynamics of science and technology. Sociology of science in the real world. Londres: The Macmillan Press. 1986.

CALLON, M.: LASCOUMES, P.: BARTHE. Y. Agir dans un monde incertain. Essai sur la démocratic technique. Paris: Seuil. 2001.

DOUGLAS. M. Risk and blame. Essays in cultural theory. Londres: Routledge. 1994.

ESRC. Global Environmental Change Programme the politics of G.M food: Risk. science \& public trust. Special brieling n. 5. October. 1999.

EUROPEAN UNION. White paper on food safetw. Disponivel $\mathrm{cm}:<$ http:/curopa.eu.int/comm> $\Lambda$ cesso cm: 2000.

FAO/WIIO. Risk management and food salety. FlO food and nutrition paper, n. 65. 1997.

FISCHLER, C. Food habits, social change and tje nature/culture dilemma. Social Science Information, [ S. 1.]: v. 19, n. 6. 1980.

GIDDI:NS. A. Modernity and Self-Identity: Self and Society in the Late Modern Age. Stanford: Stanford University Press, 1991.

GIDDENS, A. Living in a Post-Traditional Socicty. In: BLCK. U.: GIDDENS, A.: LASH, S. Reflexive Modernization. Politics. Traditions and Aesthetics in the Modern Social Order. Cambridge: Polity Press, 1994a.

GIDDENS, A. Beyond lefi and Right. The Future of Radical Politics. Cambridge: Polity Press. $1994 \mathrm{~b}$.

GIDDENS, A. Alluence, poverty and the idea of a postscarcity society. Development and (hange, [S.1.], v. 27. p. 365-377, 1996.

GREEN ALLIANCE. Steps into Uncertainty: Ilandling risks and uncertainty in environmental policy-making. London: Green Alliance, 2000.

GROVE-WHITE. R. Afterword: on "sound science". the environment, and political authority. Environmental l'alues. [S. 1.]. n. 8, 1999.
GROVL-WIITI: R.: MACNAGHTLN. P.: WYNNI: B. Uncertain world: Genetically Modified Organism. food and public attitudes in Britain. $\Lambda$ research report by the Centre for the Study of linvironmental Change. Lancaster: Lancaster University. 1997.

GROVL-WHITE, R.: MACNAGITTEN. P.: WYNNE: B.: Hisining $u$. The public and new technologies. $\triangle$ research report by the Centre lor the Study of Lnvironmental Change. L ancaster: lancaster University. 2000.

GUIVANT, J. Heterogeneidade de conhecimentos no desenvolvimento rural sustentável. Cadernos de Ciênciae Tecnologia, Limbrapa, v. 14, n. 3, set./dez. 1997.

GUIVANT. J. A trajetória das análises de risco: da periferia ao centro da teoria social. Revista Brasileira de Informação Bibliografica em Cièncias Sociais, ANPC) S. I S. I. I. n. 46. 1998.

GUVANT. J. Rellexividade na sociedade de riseo: os agrotóxicos nos alimentos. In: III:RCULANO. S. (Org.). (Jlacllidade de vida e riscos ambientais. Niteroi: liditora da UFI. 2000 .

GUIVANT. I. A leoria da sociedade de risco de Ulrich Beck: entre o diagnóstico e a profecia. Estudos Sociedade e Agricultura. | S.I.|. n. 16. p. 95-112. 2000.

GUIVANT. J. I leterogeneous and unconventional coalitions around global food risks: integrating Brazil into the debates. Journal of Environmental Policy and Planning, | S. I. | v. 3. n. 2. p. $231-245.2002$.

GUIVANT, J. : MIRANDA, C. As duas caras de Jano: agroindústrias e agricultura familiar diante da questão ambiental. Cadernos de Ciência e Tecnologia, Limbrapa. v. 16. n. 3, set. dez. 1999.

IIANNINGAN. A. Emvironmental Sociology. A social constructivist perspective. Londres: Routledge. [19-]

IRWIN. A Citizen Science. A study of people. expertise and sustainable development. Londres: Routledge. 1995.

IRWIN, A. Sociology and the emironment. Londres: Polity Press. 2001.

I.ATOUR. B. Science in action. Ilow to follow scientists and engineers through society. Cambridge. Massachusetts: I larvard University Press. 1987.

LATOUR. B. To modernize or to ecologies? That is the question. In: BRAUN, B.: CASTREL: N. (Orgs.). Remaking reality. Nature at the millennium. Londres: Routledge. 1998. 
LATOUR, B. Jamais fomos modernos. São Paulo: Editora 34, 1999.

LAW, J. ; HASSARD, J. (Orgs.). Actor-Network theory and after. London: Blackwell; 1999.

MOL, A. ; SPAARGAREN, G. Environment, Modernity and the Risk-Society: the Apocalyptic Horizon of Environmental Reform. International Sociology, [S. 1.], v. 8, n. 4, p. 431-459, 1993.

NATIONAL RESEARCH COUNCIL. Science and judgment in risk assessment. Washington: Taylor and Francis, 1996.

NATIONAL RESEARCH COUNCIL/INSTITUTE OF MEDICINE. Ensuring safe food. From production to consumption. Washington: National Academy Press, 1998.
POWELL, D.; LEISS, W. Mad cows and mother's milk. The perils of poor risk communication. Quebec: McGill-Queen's University Press, 1997.

WYNNE, B. Risk management and hazardous waste. Implementation and the dialectics of credibility. Berlin: Springer-Verlag, 1987.

WYNNE, B. Frameworks of rationality in risk management: towards the testing of naive sociology. In: BROWN, J. (Ed.). Environmental threats: perception, analysis and management. London: Belhaven Press, 1989.

WYNNE, B. Misunderstood misunderstanding: social identities and public uptake of science. In: IRWIN, A.; WYNNE, B. Misunderstanding science? The public reconstruction of science and technology. Cambridge: Cambridge University Press, 1996. 